$\mathrm{Oz}$

$1-1-2015$

\title{
Sugar Hill Project: Harlem, New York
}

David Adjaye

Adjaye Associates

Follow this and additional works at: https://newprairiepress.org/oz

Part of the Architecture Commons

(c) (1) $\Theta \Theta$

This work is licensed under a Creative Commons Attribution-Noncommercial-No Derivative Works 4.0 License.

\section{Recommended Citation}

Adjaye, David (2015) "Sugar Hill Project: Harlem, New York," Oz: Vol. 37. https://doi.org/10.4148/

2378-5853.1546

This Article is brought to you for free and open access by New Prairie Press. It has been accepted for inclusion in Oz by an authorized administrator of New Prairie Press. For more information, please contact cads@k-state.edu. 


\section{Sugar Hill Project \\ Harlem, New York}

\author{
David Adjaye \\ Adjaye Associates
}

Sugar Hill is a new mixed-use development in Harlem's historic Sugar Hill district that features affordable housing, a children's museum, preschool, non-profit offices, and underground parking. Initiated by non-profit developer of supportive housing, Broadway Housing Communities (BHC), and generated by a tight budget as well as the exacting parameters of the site, the concept challenges the traditional typology of low cost housing and reflects Adjaye Associates' commitment to a wider urban and cultural responsibility.

The neighboring context is a critical aspect to all of the practice's projects and in this case, we have worked closely with the client and local community through a series of workshops and planning meetings to ensure the design is tied to its history and place. The architectural response is a textured slab building, which crowns a 76-foot base that steps back at the ninth floor to create a ten foot terrace and cantilever on opposite sides. Terraces are placed on the second, third, ninth, and rooflevels. The project aims to become a new neighborhood hub and a gateway to Sugar Hill.

\section{Neighborhood}

The site sits at the juncture of three distinct communities: Hamilton Heights (West Harlem), Central Harlem, and Washington Heights. The location acts as a crossroad between the traditional and historical center of the AfricanAmerican community of Harlem and the Dominican community of Wash-
York's architecturally and historically significant neighborhoods. The row houses south of the site were built in the early twentieth century and housed middle class families-Oscar Hammerstein, George Gershwin, and Norman Rockwell all lived in the area.

The neighborhood is most famous for housing affluent African-Americans who began to move there in the 1920s and 1930s. The site bordered by 145th and 155th Street, and Edgecombe and Amsterdam Avenues was called "Sugar Hill" because of the "sweet life" that was enjoyed there. Edgecombe Avenue, particularly numbers 409 and 555 , housed illustrious members of the African-American community including W.E.B. Dubois, Thurgood Marshall, Langston Hughes, Paul Robeson, Count Basie and Zora Neale Hurston.

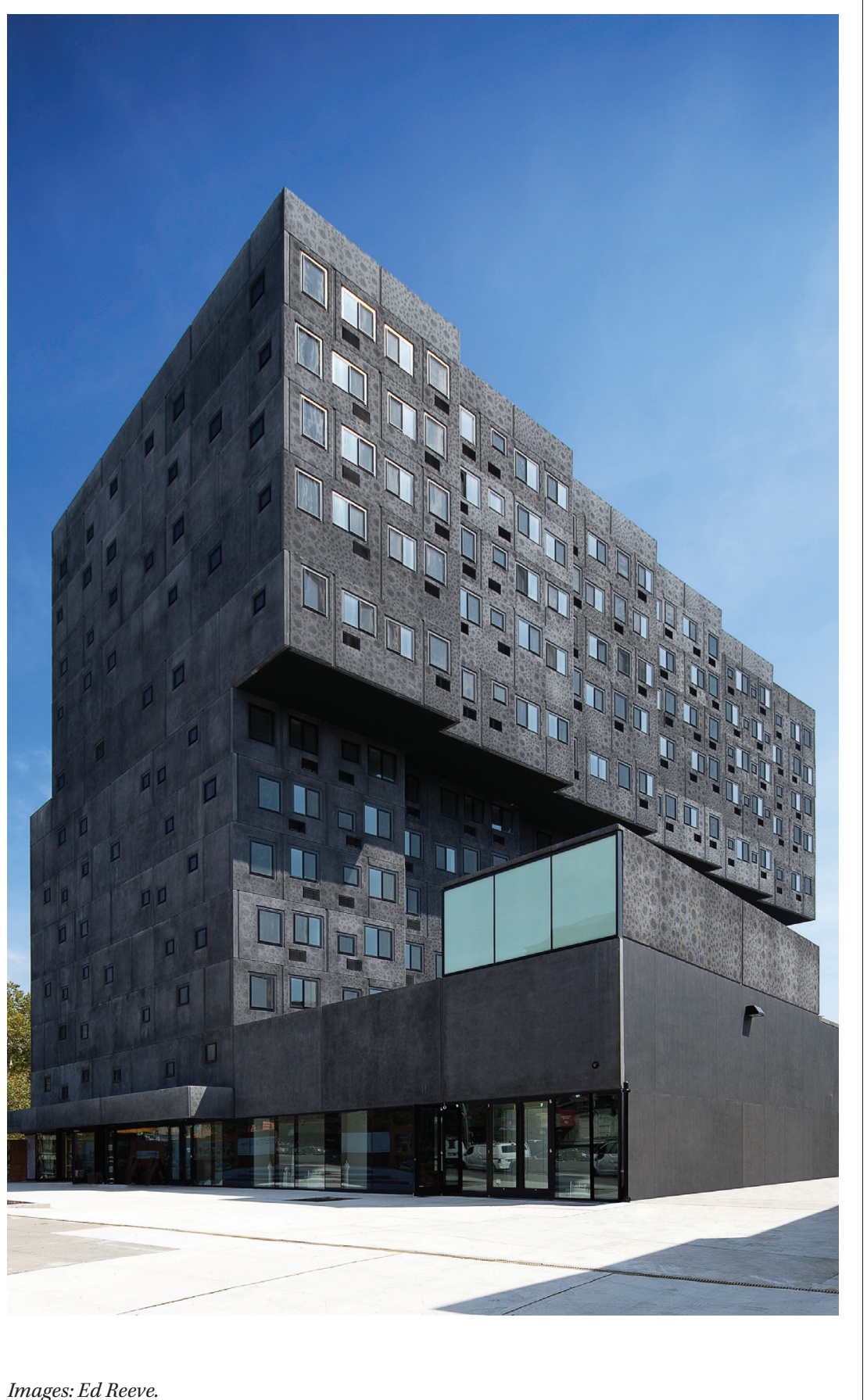




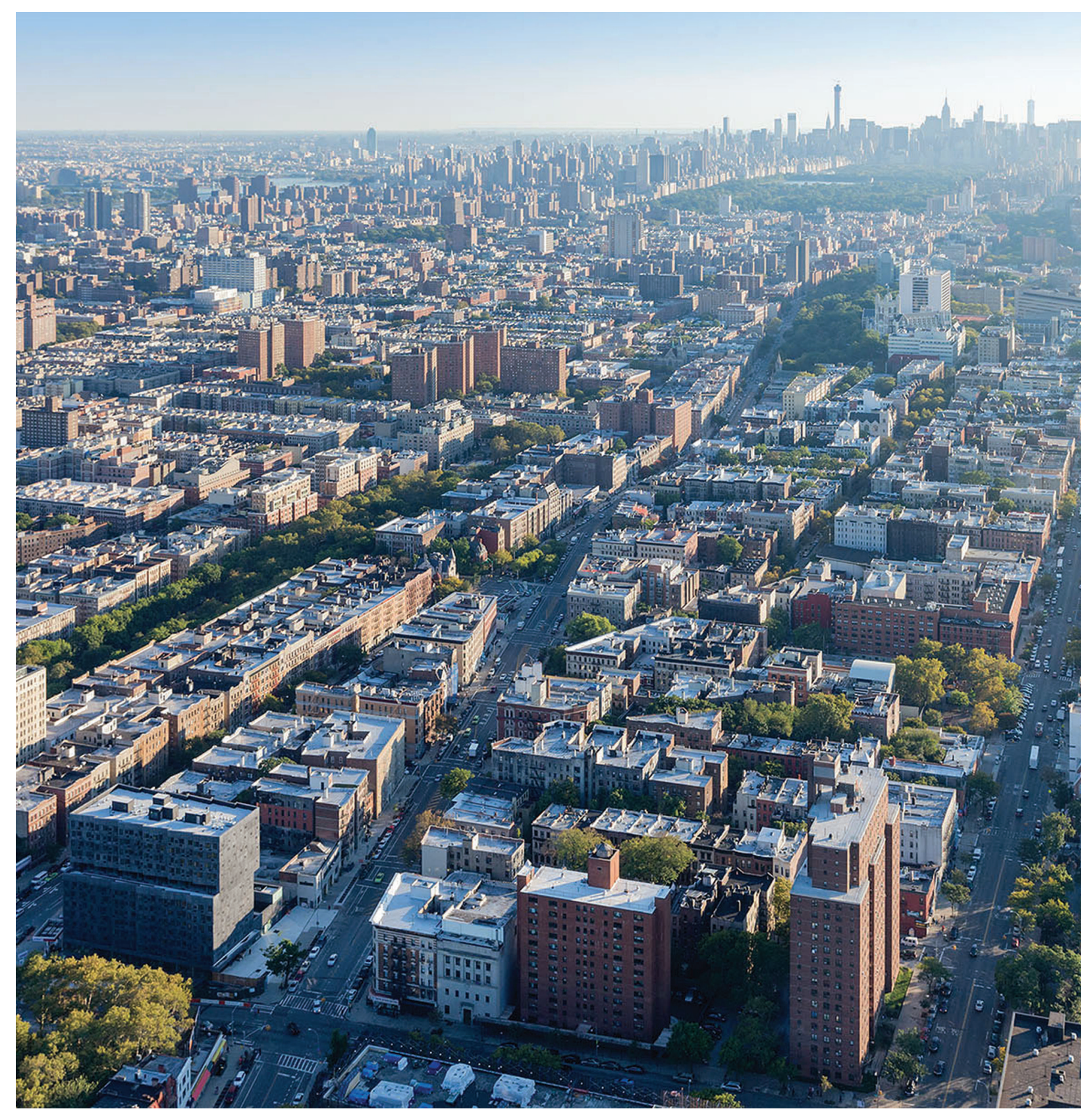




\section{Glazed Moments}

The building uses light like a primary building material. Transparent glass "moments" offset the density and depth of the rose-embossed precast panels. The second floor glass band, for example, counters the heft of the precast panels above, celebrates the views to the city, and connects the building back to its urban context. Inside, there is a full-length cut-or skylight-which offers a dramatic moment of space, air, and light at the heart of the building.
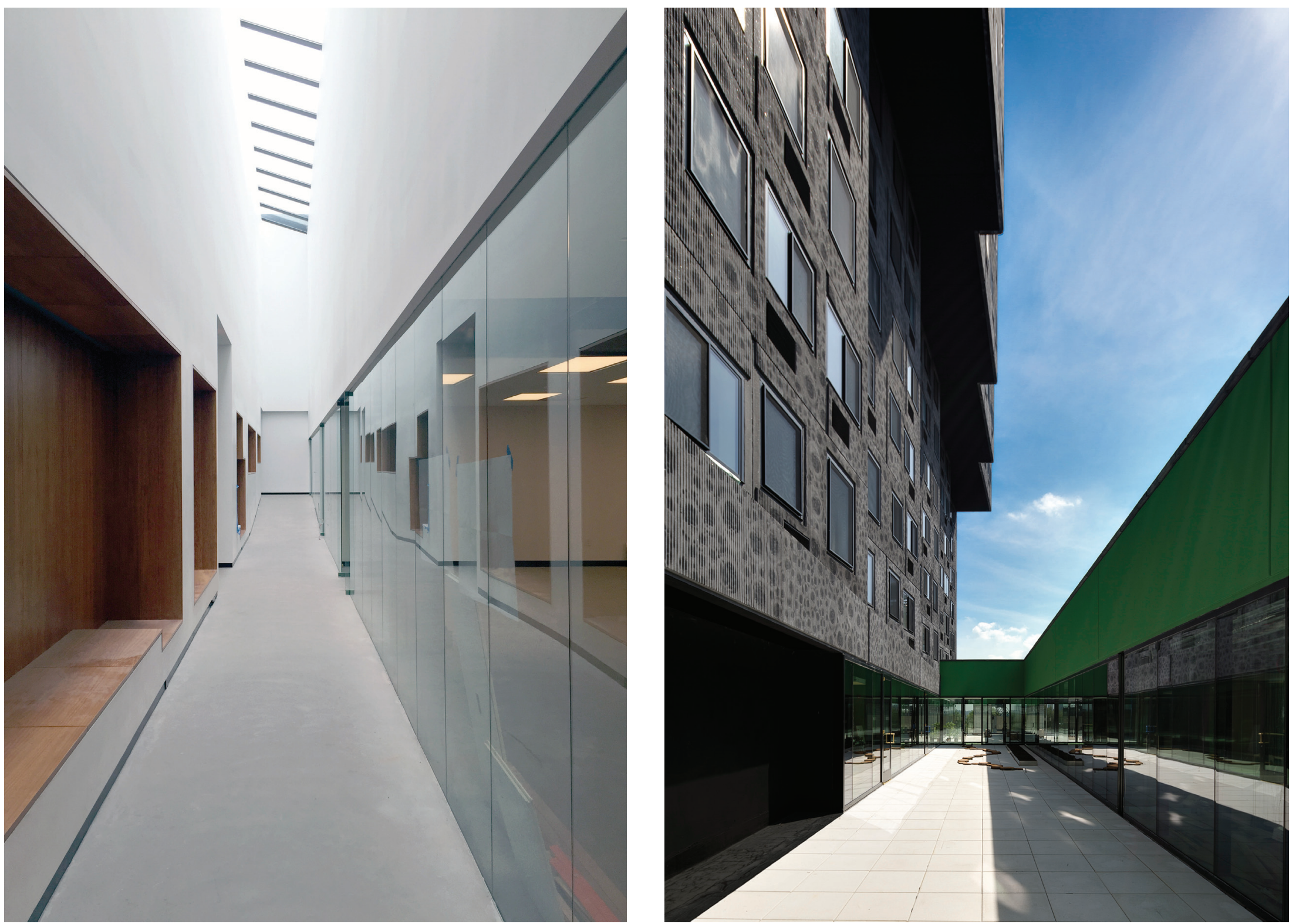


\section{Vernacular Pattern}

The Sugar Hill Historic District has a distinct language, with various tropes drawn from nature inscribed onto its buildings. One can find fern leaves, flowers, twisted vines, roses, thistles, and scrolls throughout the neighborhood. These carvings are richly expressive, both in terms of the iconography as well as the celebration of craftsmanship and pride of place.
The image shown is a selection from our early research into the area at the start of the project. The details are largely attributable to nature as opposed to geometric patterning. It is in this vein that we chose to explore the idea of roses and their ability to make patterns as flowers as well as a climbing vine.

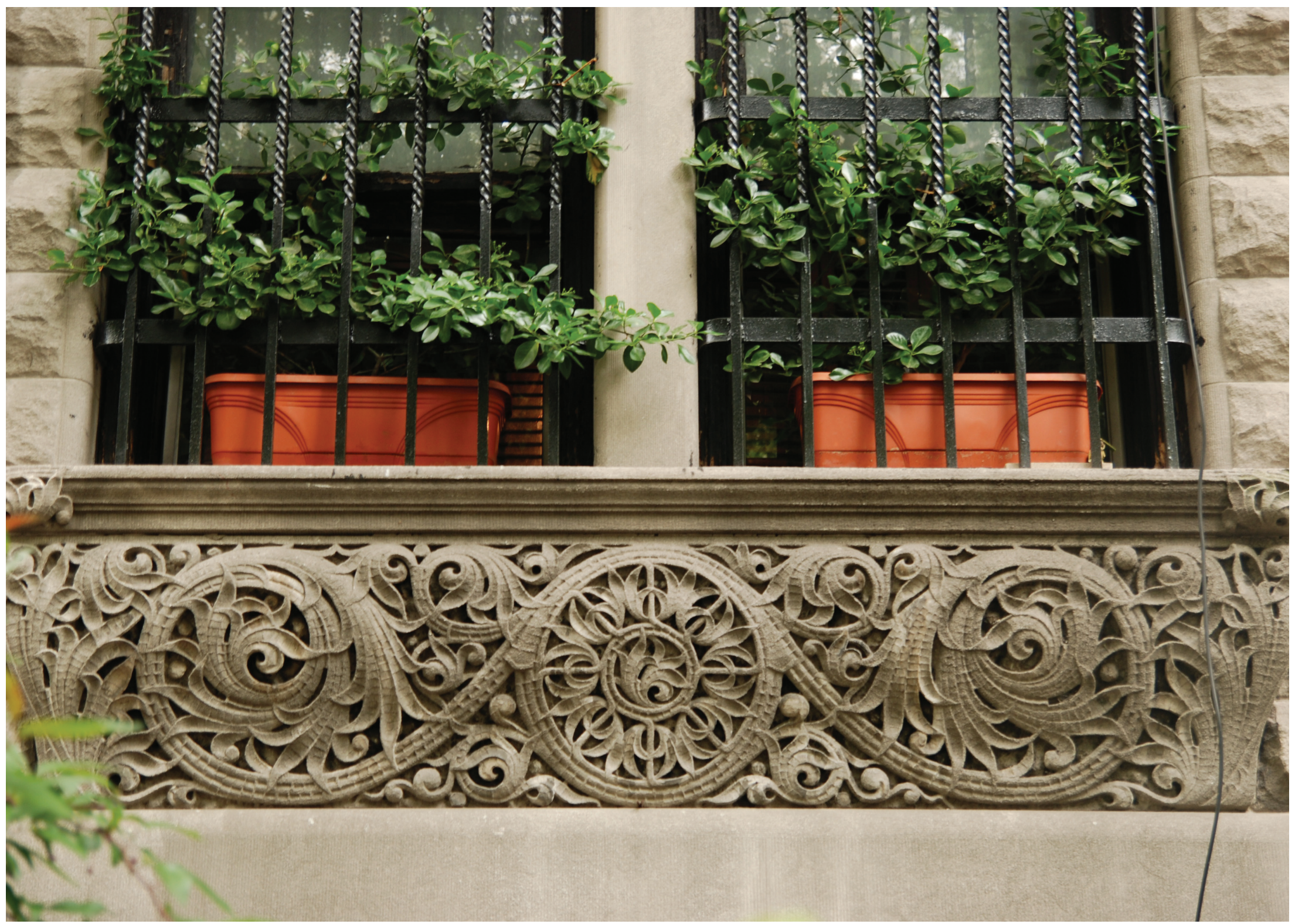




\section{Rose-Patterned Facade}

The building has a rose-patterned relief on the graphite-tinted facade that pays tribute to the rich culture and history of Harlem. The rose pattern was conceived as a classically derived ordering system for the building. The custom pattern was produced with a simple rubber-mould liner fabricated with contemporary precast concrete production techniques that allowed us to create this subtle and beautiful effect at an affordable cost. The deep gray rose pattern and saw- tooth undulations abstractly reference the intricate masonry ornament and the articulation of the row house bays of the neighboring buildings. It also resonates with the fact that the rose is the New York state flower and that the site falls within the city's "Heritage Rose District." The roses on the building facade are set to varying sizes and depths to enhance the play of light across the surface. The fenestration accentuates the vinelike qualities of the rose pattern while also providing an abundance of natural light and views from the apartments. The tinted precast concrete material was refined through a series of studies and samples. The panels are acid-washed twice and designed to sparkle in the sunlight allowing the building to shimmer throughout the day. The graphite color also serves as a contrast to the luminous glass facade that begins at the public entry plaza and wraps around the entire building creating a glowing beacon for the gateway to
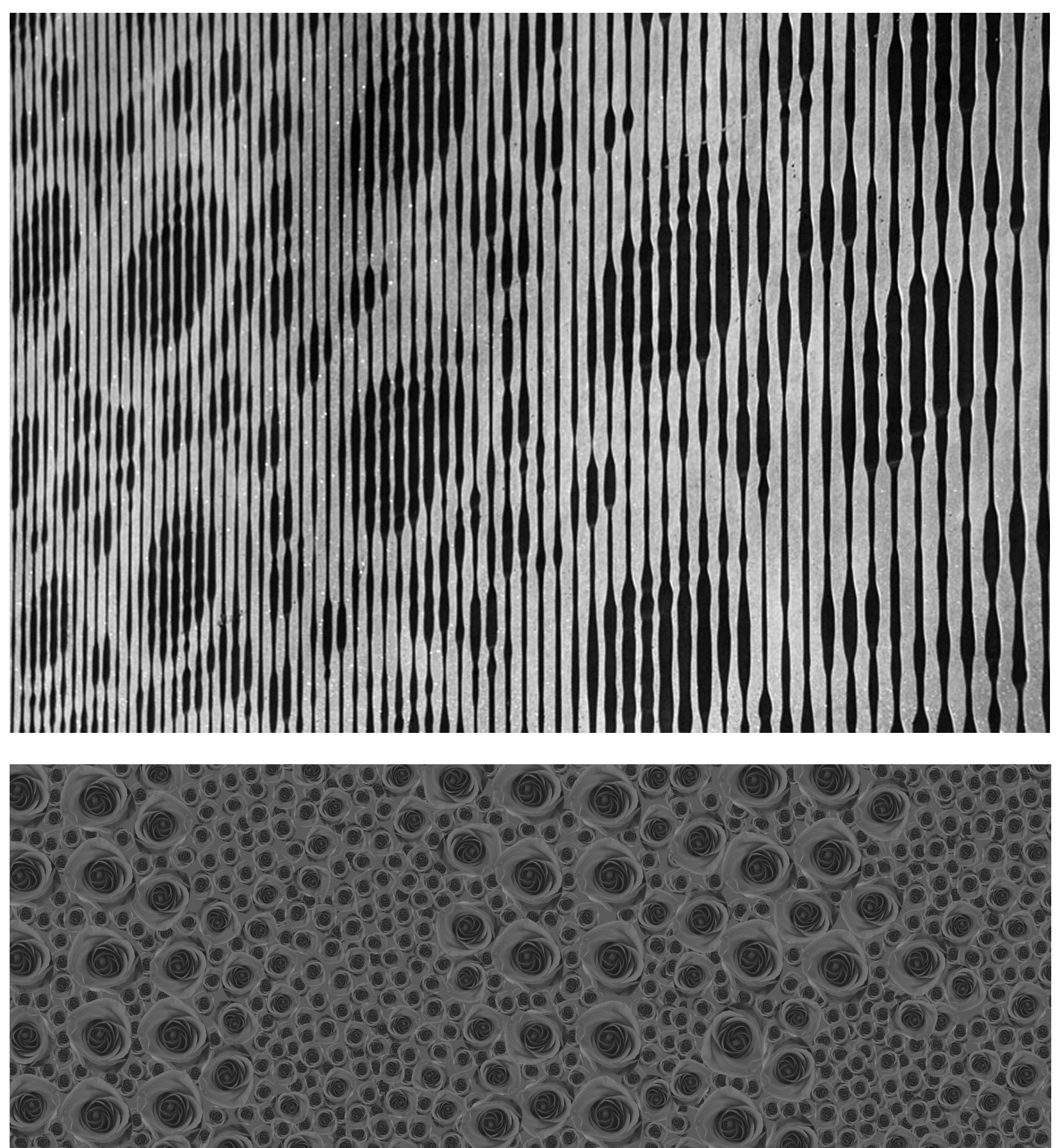


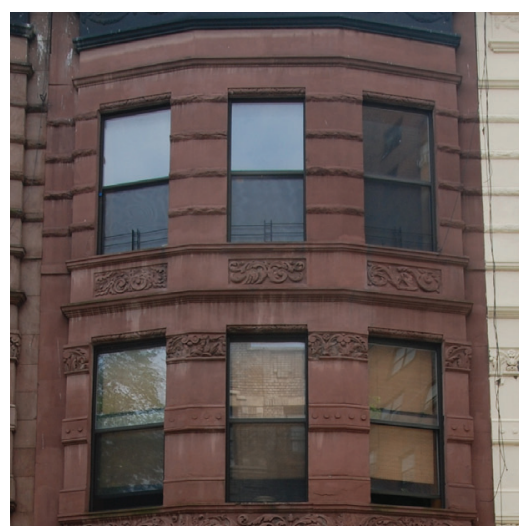

Rusticated strips

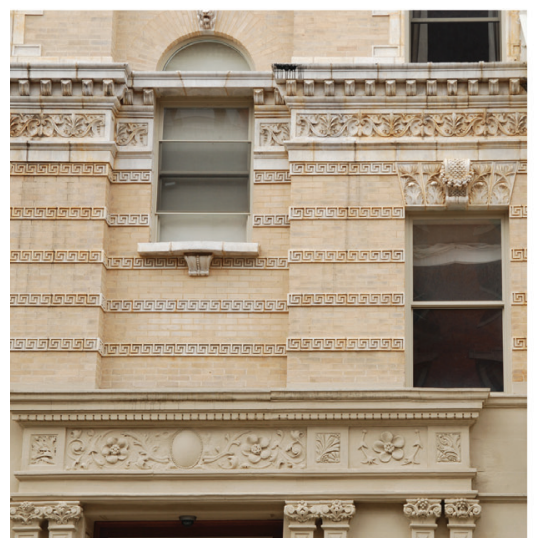

Strips of ornament

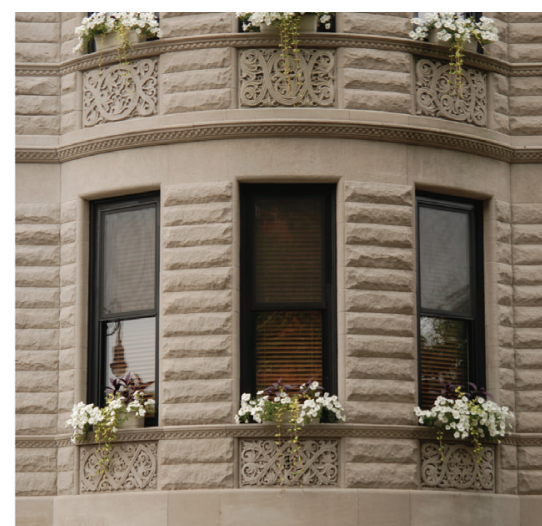

Entirely rusticated

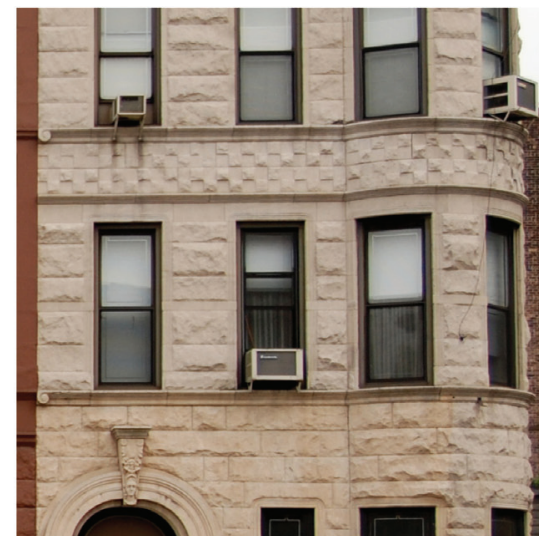

Varied rustication

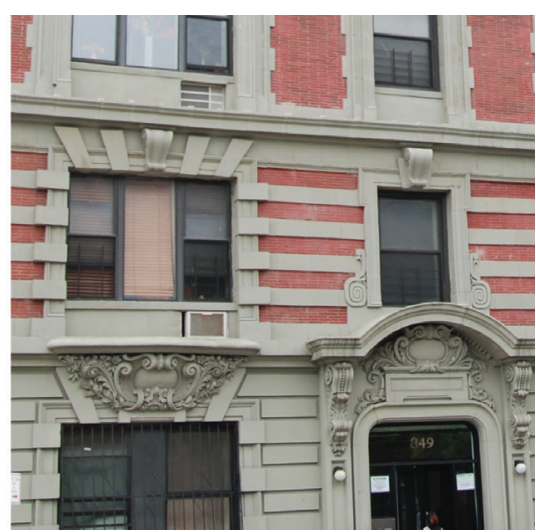

Ornamental

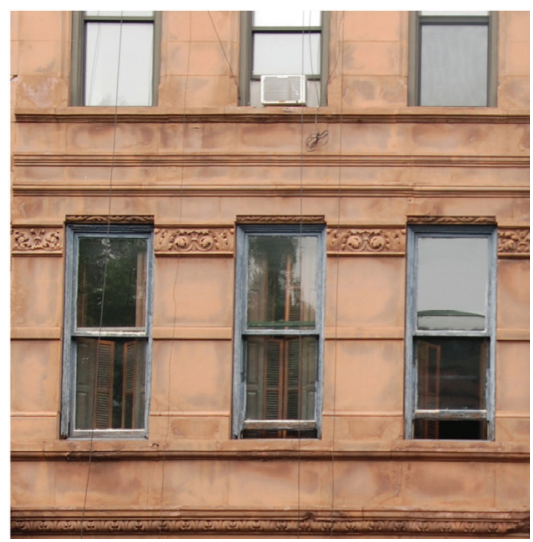

Flat with cornice strips

\section{Historic Texture}

The Gothic revival and neoclassical buildings in this area generally have highly articulated facades, from intricately detailed carvings to variegated surface textures. The carvings and textures run across building facades providing a wide spectrum of shadow and light play. Neoclassical buildings tend to work with a flattened striping and variations of architraves, keystones, cornices, and bases. Gothic revival buildings have an organic tendency in terms of materials as well as forms. Materially the buildings are picturesque with rough cut stone patterns and an integrated use of natural carving.

Using these references, the facade becomes a canvas for a play of light and shadow with a rich patterning of roses set in relief of various scales to provide a richness of visual experience across the surface of the building. 


\section{Traditional Massing}

We have focused on two types of buildings found in the historical district: neoclassical and Gothic revival. Both are quite distinct in their massing strategy, but equally important in informing the composition of our project.
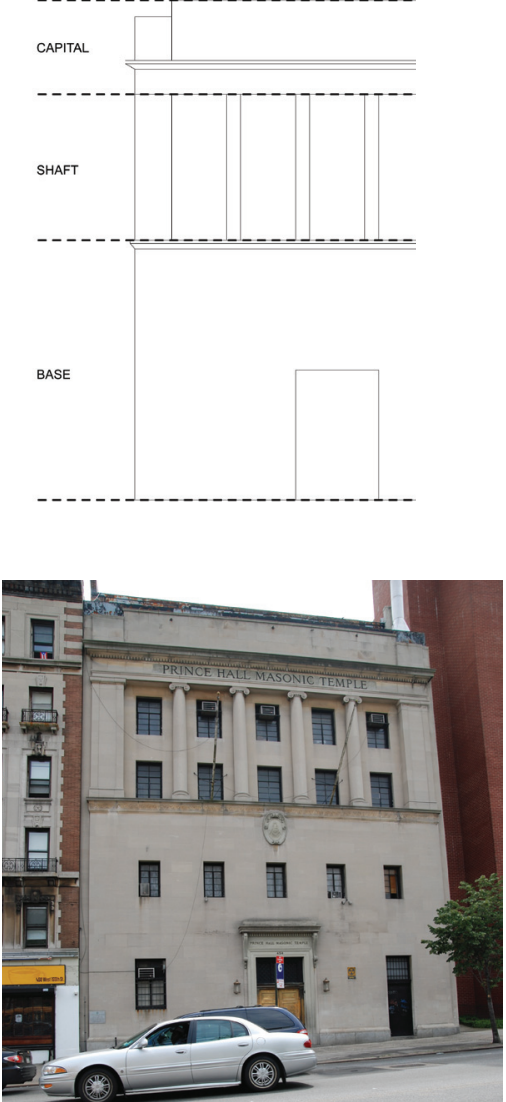

Tripartite elevation

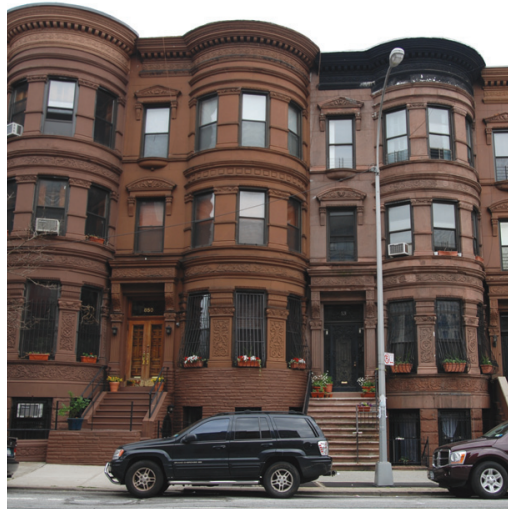

The neoclassical example-a masonic temple-is arranged vertically. It is composed of a strong twostorey base. Above this, the body of the building is articulated with a five-bay columnar structure with recessed windows and capped by a flat pediment where the institution displays its name.

The row house uses cylindrical or orthogonal projection into the street making for a sculpted frontage. We referenced this idea in developing our saw-tooth facade. Our goal was to provide visual relief and a smaller proportion and scale to the 13-storey building mass. The added sawtooth window increases the light and air in the apartments and provides vistas to the Harlem River and Yankee stadium to the east.

\section{Tripartite Massing in Sugar Hill} Like the neighboring Masonic Temple, the Sugar Hill Project also makes use of a similar structure with the precast base, flush glass at the plaza level, and six-bay sawtooth facade above. The three different massing levels reference the adjacent building heights: the low row houses to the north relate to the glass band entry and public plaza level, the taller apartment buildings to the south align with the ninth floor cantilever, and the overall building height and mass is modest in relation to the nearby typical New York City affordable housing buildings.

\section{Sawtooth Plan}

Relating to the vernacular row houses in the neighborhood we used the same sawtooth plan as a means to provide visual relief and a smaller scale to the 13-story building mass. The added sawtooth window increases the light and air in the apartments and provides vistas to the Harlem River and Yankee stadium to the east.

\section{Panel Joints}

The play of light and shadow is set within an ordered running bond pattern providing a rich texture across the surface and a rigid framework for the rose vines to rise up the facade.

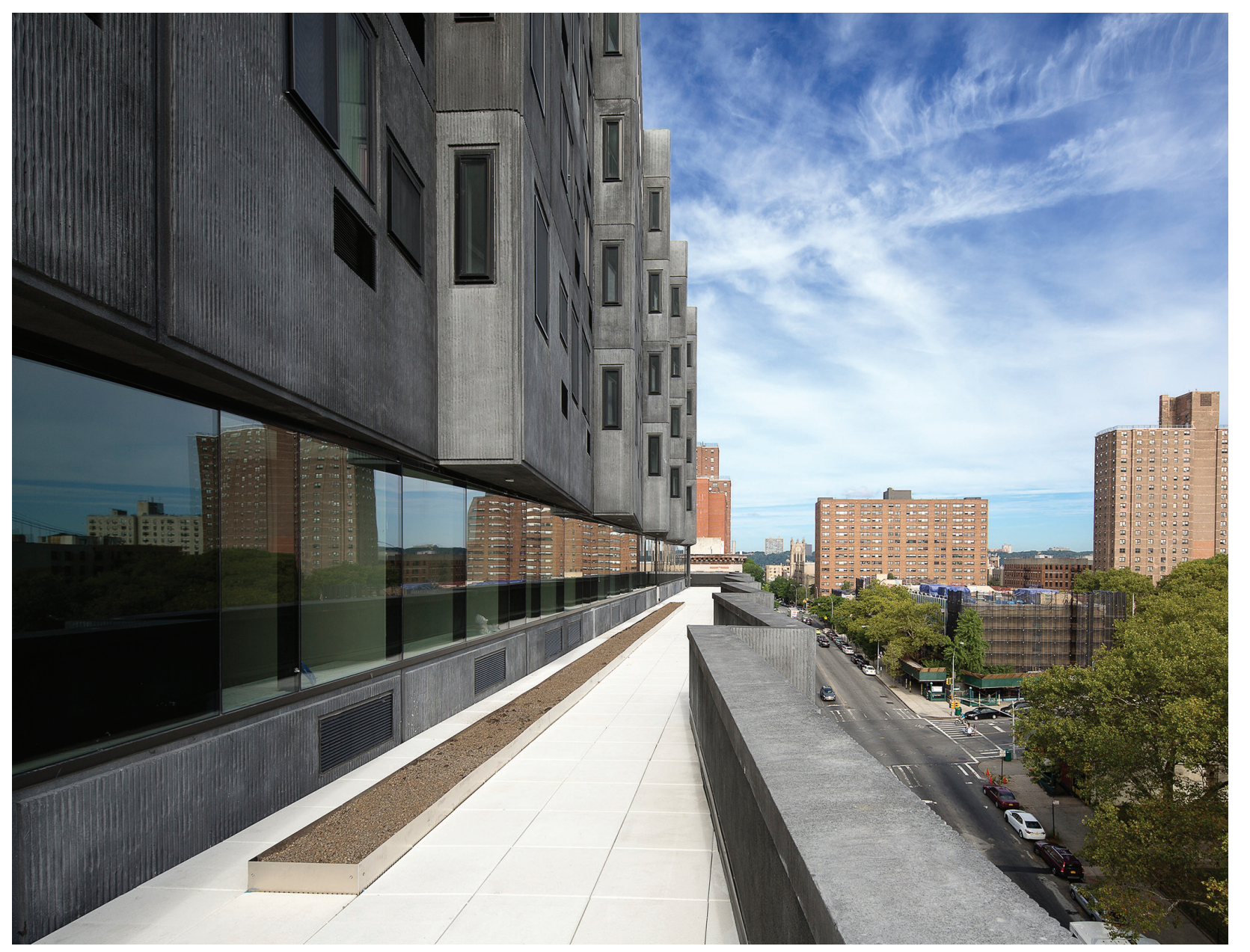



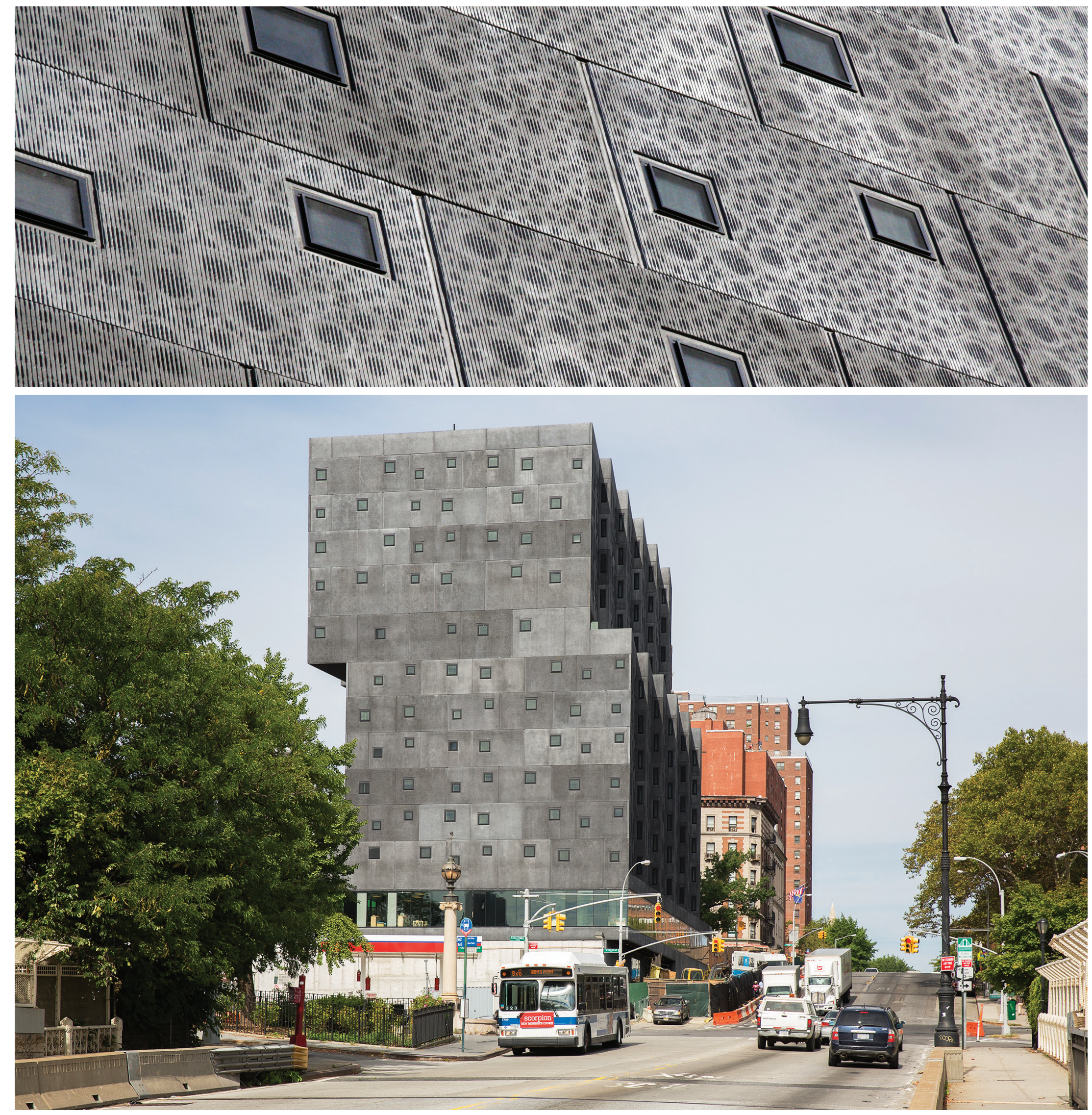